\title{
KESANTUNAN LINGUISTIK PADA KOMUNIKASI MELALUI PESAN WHATSAPP SAAT BEKERJA DARI RUMAH SELAMA PANDEMIK COVID-19
}

\author{
Ilmatus Sa'diyah \\ Universitas Pembangunan Nasional "Veteran" Jawa Timur \\ ilmatus.sisfo@upnjatim.ac.id
}

\begin{abstract}
Abstrak
Aspek utama yang lebih banyak dipertimbangkan saat berkomunikasi secara tertulis dengan orang lain melalui whatsApp adalah kesantunan. Bahkan, pertimbangan kesantunan jauh lebih tinggi daripada maksud pesan di dalamnya. Walaupun whatsApp sudah dilengkapi dengan beragam ekspresi (emoticon), hal itu belum cukup untuk menampilkan kesantunan linguistik pengirim pesan. Oleh karena itu, analisis kesantunan linguistik pada pesan tertulis yang dikirim melalui pesan whatsApp perlu dilakukan. Secara khusus, penelitian ini bertujuan mengidentifikasi bentuk, strategi, dan fungsi kesantunan linguistik pada komunikasi melalui pesan whatsApp selama masyarakat bekerja dari rumah pada pandemik covid-19. Teori kesantunan yang digunakan dalam penelitian ini adalah teori kesantunan Leech pada fungsi kesantunan (1993) dan bentuk kesantunan oleh Oktavianus dan Revita pada bentuk kesantunan (2013). Penelitian ini merupakan penelitian kualitatif. Data penelitian ini berasal dari pesan tertulis di whatsApp yang masuk ke peneliti. Data pengirim pesan tidak ditampilkan. Data dianalisis dengan metode padan pragmatik dan kontekstual. Berdasarkan hasil analisis, ditemukan 3 bentuk kesantunan dan 5 fungsi kesantunan. Bentuk kesantunan meliputi kesantunan meminta, bertanya, dan memuji. Fungsi kesantunan meliputi fungsi kompetitif, menyenangkan, kerja sama, dan bertentangan.
\end{abstract}

Kata kunci: kesantunan linguistik, kesantunan pesan tertulis, fungsi kesantunan, bentuk kesantunan

\section{PENDAHULUAN}

Dalam berkomunikasi dengan orang lain, kesantunan menjadi prioritas utama daripada kejelasan pesan yang ingin disampaikan. Penutur akan berhati-hati dalam memilih bahasa agar saat berkomunikasi tidak ada pihak yang dirugikan atau tersinggung karena kesalahan dalam pemilihan bahasa. Tak hanya itu, dengan menggunakan kesantunan dalam berkomunikasi, kenyamanan akan terbentuk selama berkomunikasi dan memberikan rasa hormat dari penutur kepada lawan tuturnya. Oleh karena itu, Anugrah, Revita, \& Marnita (2020) menyatakan bahwa kesantunan adalah strategi yang digunakan penutur untuk membentuk keterbukaan antara penutur dengan lawan tuturnya.

Selain itu, kesantunan berbahasa menjadi cara untuk mengenali karakter seseorang. Rahayu (2019) menyatakan bahwa kesantunan berbahasa erat kaitannya dengan martabat seseorang, baik selama menggunakan bahasa secara lisan maupun secara tertulis dalam bentuk media apa pun. Dari bahasa seseorang, kesantunan dapat terdeteksi dari komunikasi penutur sehingga bisa digunakan oleh lawan tutur untuk memberikan respons.

Saat pandemik Covid-19 berlangsung sejak Maret 2020, masyarakat diminta melakukan kegiatan belajar dan bekerja dari rumah untuk mendukung program pemerintah dalam mengurangi jumlah pasien Covid-19. Aktivitas yang beralih ke rumah ini menyebabkan cara berkomunikasi pun berubah. Sebelum Covid-19, masyarakat cenderung menyukai cara berkomunikasi secara langsung tatap muka di tempat. Kini, komunikasi harus berlangsung secara virtual dengan memanfaatkan beragam media, misalnya whatsApp, zoom meeting, google meet, instagram, maupun media lainnya. 
Komunikasi melalui whatsApp lebih banyak dipilih oleh masyarakat karena gratis, memiliki fitur komunikasi yang lengkap, dan memiliki pengguna sangat banyak di seluruh dunia, termasuk Indonesia. Oleh karena itu, komunikasi melalui media itu dipilih sebagai sumber data dalam penelitian ini. Selain itu, interaksi antara pengirim pesan dan penerima pesan menunjukkan kesantunan linguistik yang memadai. Hal itu dilakukan agar proses komunikasi berlangsung secara nyaman dan tujuan masing-masing dapat tercapai selama bekerja dari rumah. Pengirim pesan menggunakan kesantunan untuk mendapatkan informasi atau memberikan informasi berupa instruksi yang berkaitan dengan pekerjaan, begitu pula dengan penerima pesan. Kesantunan rupanya menjadi prinsip kerja sama di antara keduanya.

Penelitian ini pun dilakukan untuk menggali lebih dalam bentuk dan fungsi kesantunan berbahasa secara tulis melalui media whatsApp selama bekerja dari rumah. Dalam konteks pekerjaan, cara berkomunikasi yang santun tentu menjadi tantangan bagi para penutur agar pekerjaan bisa berlangsung optimal.

\section{LANDASAN TEORI}

\section{Penelitian Terdahulu yang Relevan}

Pada dasarnya, penelitian dengan topik kesantunan linguistik atau kesantunan berbahasa sudah dilakukan oleh peneliti sebelumnya dengan konteks yang berbeda. Perbandingan antara penelitian terdahulu dengan penelitian ini tergambar detail dalam diagram 1. Penelitian pertama dilakukan oleh Rahayu (2019) yang berjudul “Analisis Kesantunan Berbahasa Media Sosal Instagram: Kajian Pragmatik”. Penelitian ini dilakukan untuk mengetahui kesantunan berbahasa pada tuturan komentar publik terhadap postingan Jokowi di instagram. Setelah dianalisis, kesantunan berbahasa di komentar itu menunjukkan tuturan yang santun. Sementara pada penelitian ini media sosial yang digunakan adalah whatsApp dengan konteks komunikasi selama bekerja dari rumah.

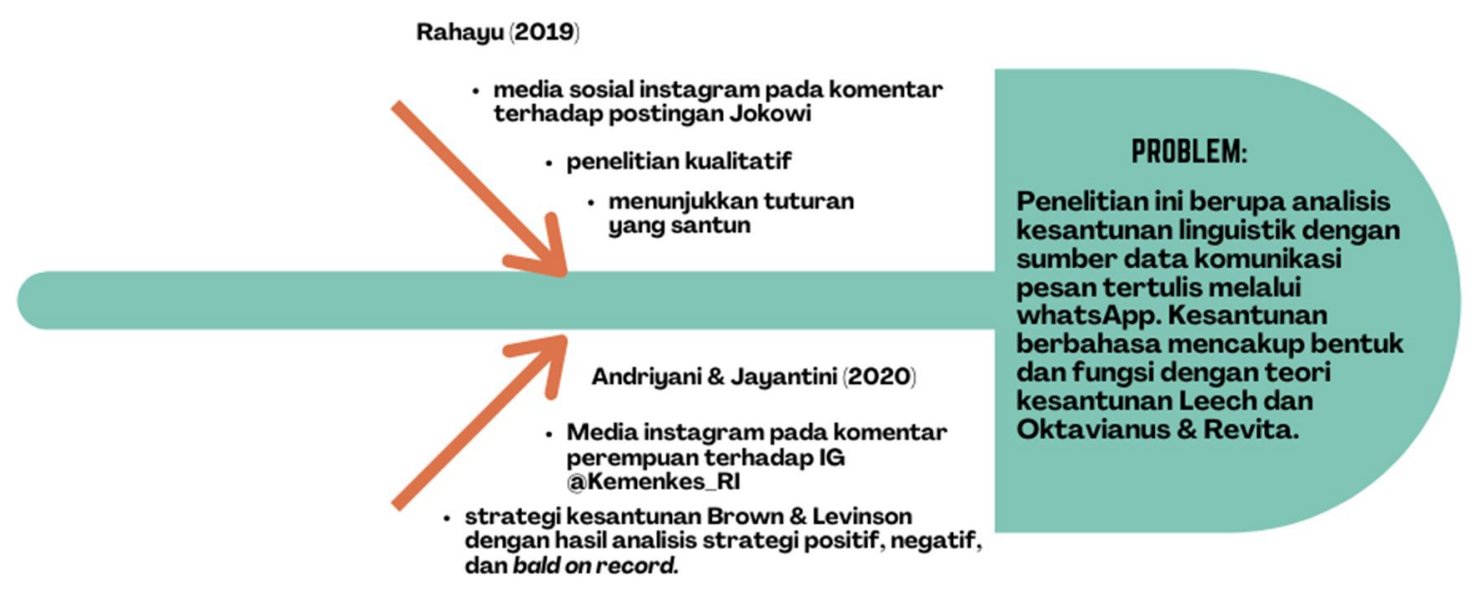

Diagram 1. Perbandingan Penelitian Terdahulu 
Penelitian kedua dilakukan oleh Andriyani \& Jayantini (2020) dengan judul "Perempuan dan Pesan di Media Sosial pada Masa Pandemi Covid-19: Analisis Strategi Kesantunan”. Penelitian ini menggunakan data berupa dialog dalam unggahan di media sosial instagram Kementerian Kesehatan Republik Indonesia @ kemenkes_RI. Hasil penelitian menunjukkan bahwa strategi kesantunan yang digunakan oleh perempuan adalah stategi positif, negative, dan bald on record. Penelitian ini menunjukkan perbedaan dengan penelitian yang akan dilakukan pada aspek sumber data yang digunakan dan teori kesantunan berbahasa yang digunakan.

\section{Kesantunan Linguistik}

Kesantunan linguistik disebut juga sebagai kesantunan berbahasa. Kesantunan itu tecermin dalam komunikasi antarpenutur dalam bentuk verbal maupun cara berbahasa. Rahayu (2019) menyatakan bahwa saat berkomunikasi, penutur tidak hanya menyampaikan gagasan dalam pikirannya, tetapi juga patuh pada norma-norma budaya yang ada di masyarakat. Ketika penutur mengabaikan norma budaya yang berlaku, penutur itu akan mendapatkan anggapan negatif dari masyarakat sekitarnya, seperti anggapan sebagai orang yang sombong, egois, tak acuh, tidak berbudaya, dan tidak beradat.

Untuk menganalisis kesantunan linguistik, data yang digunakan disebut sebagai peristiwa tutur. Chaer (2010:47) menjelaskan bahwa peristiwa tutur merupakan proses terjadinya interaksi linguistik dalam bentuk ujaran atau lebih yang melibatkan lawan tutur dan penutur dengan satu pokok tuturan pada waktu, tempat, dan situasi tertentu. Dalam hal ini, peristiwa tutur yang digunakan berupa komunikasi melalui pesan WhatsApp selama bekerja dari rumah karena pandemik covid-19.

Pada setiap peristiwa tutur yang dianalisis, kesantunan berbahasa akan menunjukkan keunikan cara berbahasa karena berbenturan dengan budaya yang ada. Dalam hal ini, latar belakang penutur sangat berpengaruh dalam membentuk cara berkomunikasi penutur di tengah masyarakat, termasuk latar belakang budaya. Penutur dari Medan dengan penutur dari Jakarta tentu memiliki perbedaan dalam berkomunikasi. Jauhari (2018) menyatakan bahwa kesantunan berkaitan dengan kesantunan sosial atau kesantunan kultural yang sensitif terhadap keberadaan konteks.

\section{Bentuk Kesantunan}

Oktavianus \& Revita (2013:84-114) mengklasifikasikan bentuk kesantunan menjadi sepuluh jenis. Keseluruhan bentuk kesantunan itu meliputi kesantunan meminta, kesantunan menolak, kesantunan bertanya, kesantunan menyuruh, kesantunan berjanji, kesantunan berekspresi, kesantunan memuji, kesantunan memberi, kesantunan saat emosi, dan kesantunan saat gembira.

Kesantunan meminta berkaitan dengan tindakan meminta dari pengirim pesan. Tindakan itu tidak bisa dihindari karena sudah menjadi bagian dalam kehidupan manusia sehingga perlu disampaikan dengan bahasa yang santun agar permintaan dari pengirim pesan dapat terwujud dari penerima pesan. Lawan dari kesantunan meminta adalah kesantunan menolak. Siapa pun yang mendapatkan permintaan berhak untuk 
menolak. Namun, mayoritas penolakan dapat menyinggung pengirim pesan, bahkan dapat menciptakan konflik. Oleh karena itu, dalam menolak pun dibutuhkan kesantunan yang memadai agar terhindar dari halhal itu. Lain lagi dengan kesantunan bertanya yang sebenarnya justru memberikan beban bagi penerima pesan karena pengirim pesan membutuhkan respons.

Kesantunan berikutnya adalah kesantunan menyuruh. Kesantunan ini dibutuhkan untuk tujuan memberikan instruksi kepada penerima pesan untuk melakukan hal yang diminta oleh pengirim pesan. Kesantunan berjanji merupakan kesantunan yang bisa dilakukan oleh kedua pihak dalam berkomunikasi. Dalam hal ini, janji adalah utang sehingga perlu ditepati oleh yang memberi janji. Kesantunan berekspresi dianggap jenis kesantunan yang sangat dibutuhkan karena saat berkomunikasi, penerima dan pengirim pesan cenderung lepas kendali dalam berekspresi sehingga bisa saja menimbulkan konflik. Selanjutnnya, kesantunan memuji sering diungkapkan dalam berkomunikasi untuk memberikan rasa senang kepada penerima pesan.

Kesantunan kedelapan adalah kesantunan memberi. Dalam kehidupan, memberi menjadi wujud kasih saying. Dalam hal ini, memberi digunakan oleh pengirim pesan untuk memberikan informasi secara cuma-cuma kepada penerima pesan. Dalam memberi, kesantunan sudah terasa meskipun bahasa yang digunakan belum bisa menyenangkan penerima pesan karena pemberian itu sudah menyenangkan. Berikutnya, kesantunan saat emosi memperlihatkan respons penerima dan pengirim pesan saat berkomunikasi. Respons ini tentu bersifat subjektif, tetapi tetap harus menunjukkan kesantunan. Terakhir, kesantunan saat gembira dibutuhkan sebagai pembatas agar kegembiraan yang diluapkan dalam berkomunikasi tidak berlebihan dan melebihkan.

\section{Fungsi Kesantunan}

Kesantunan dalam komunikasi memiliki beberapa fungsi. Leech (1993:162) membedakan empat fungsi yang dimiliki oleh kesantunan. Fungsi itu meliputi fungsi kompetitif, fungsi menyenangkan, fungsi kerja sama, dan fungsi bertentangan. Fungsi kompetitif berkaitan dengan tujuan sosial dari manusia. Fungsi ini mencakup tujuan memerintah, mengemis, menuntut, dan meminta. Kesantunan berfungsi untuk mewujudkan seluruh cakupan itu dari pengirim pesan sehingga penerima pesan tidak merasa terpaksa dalam melakukannya. Jadi, fungsi ini lebih mengarah pada kesantunan yang bersifat negatif. Sementara itu, fungsi menyenangkan mencakup aspek mengajak, menyapa, menawarkan, mengucapkan selamat, dan mengucapkan terima kasih. Fungsi ini mengandung kesantunan positif untuk mendekatkan satu sama lain antara pengirim pesan dan penerima pesan.

Fungsi yang ketiga adalah fungsi kerja sama. Leech (1993:162) menyatakan bahwa fungsi ini tidak relevan dengan kesantunan karena tidak bertujuan sosial. Cakupan fungsi ini meliputi melaporkan, menyatakan, mengumumkan, dan mengajarkan. Terakhir, fungsi bertentangan juga tidak mengandung unsur kesantunan karena sifatnya yang bertentangan antara pengirim pesan dengan penerima pesan. Bahkan Leech 
menyebut jika fungsi ini bertujuan memancing kemarahan lawan tutur. Cakupan fungsi ini meliputi menuduh, menyumpahi, memarahi, dan mengancam.

\section{HASIL PENELITIAN DAN PEMBAHASAN}

Penelitian ini dilakukan untuk mengkaji kesantunan linguistik antarpekerja selama bekerja dari rumah ketika Covid-19. Kajian in berfokus pada bentuk kesantuan dan fungsi kesantunan.

\section{Bentuk Kesantunan}

Berdasarkan analisis yang sudah dilakukan, ada beberapa bentuk kesantunan yang digunakan oleh pekerja selama bekerja dari rumah. Dalam hal ini, pekerja yang dimaksud adalah dosen. Berikut ini adalah bentuk kesantunan yang banyak digunakan selama berkomunikasi melalui whatsApp (WA).

\section{Kesantunan Bertanya}

Bentuk kesantunan ini paling banyak digunakan selama berkomunikasi di dalam grup WA, terutama di lingkungan pekerja baru. Pertanyaan berkaitan dengan pekerjaan yang akan dikerjakan. Bentuk pertanyaan beragam berdasarkan tujuan masing-masing. Pertanyaan bisa berupa pertanyaan untuk mendapatkan informasi atau sekadar mengonfirmasi pekerjaan yang akan dilakukan.

Gambar 1 menunjukkan bentuk pertanyaan untuk mendapatkan informasi tentang alasan tertolaknya ajuan hingga kedua kalinya. Meskipun pertanyaan disampaikan dalam tiga pertanyaan, pengirim pesan menyertakan dua kata yang menjadi penanda kesantunan, yaitu kata maaf dan ijin. Dengan dua kata itu, penerima pesan tidak merasa ditekan dengan banyaknya pertanyaan yang diajukan dalam sekali pesan yang dikirimkan.

\section{Maaf pak, ijin bertanya kalau boleh tau kenapa ditolak sampai dua kali ya? Apa ada alasannya? Apakah ada dokumen kami yang kurang sehingga masih perlu dilengkapi? \\ 09.53}

Gambar 1. Pertanyaan yang Mengandung Kesantunan Bertanya 1

Selanjutnya, pada gambar 2 berikut, pertanyaan diajukan untuk mendapatkan informasi terkait dengan pekerjaan. Kesantunan dalam pertanyaan itu terlihat dari ucapan salam yang digunakan. Bahkan, salam yang digunakan sebanyak dua versi untuk memberikan kenyamanan kepada penerima pesan di grup WA dengan agama yang berbeda. Selain salam, pengirim pesan juga menggunakan kata izin sebelum bertanya. Penggunaan kata itu dapat meningkatkan kesantunan dalam berkomunikasi. Penggunaan kata nggeh mendukung rasa nyaman selama berkomunikasi untuk penerima pesan yang sama-sama berasal dari Jawa. 
Assalamualaikum. Selamat sore.. izin bertanya. Dosen pariwisata di grup ini siapa, nggih?

Gambar 2. Pertanyaan yang Mengandung Kesantunan Bertanya 2

\section{Kesantunan Memuji}

Kesantunan berikutnya yang juga mendominasi komunikasi di grup WA adalah kesantunan memuji. Setiap ada kesuksesan yang didapatkan oleh peserta grup, anggota grup pasti mengirimkan pesan berisi kalimat pujian. Tak hanya kesuksesan, jika ada anggota grup yang baru saja mendapatkan kebahagiaan berupa kelahiran atau pernikahan, ungkapan pujian juga disampaikan di grup. Pada gambar 3, terdapat pesan berisi pujian bagi anggota grup yang baru melahirkan anak pertamanya. Pilihan kata yang digunakan sangat santun. Ada pilihan kata Alhamdulillah dan semoga sehingga menunjukkan kesantunan yang tinggi. Emotikon mata penuh cinta pun digunakan dalam pesan itu.

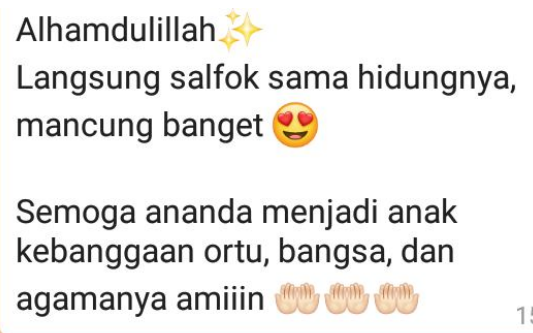

Gambar 3. Ungkapan yang Mengandung Kesantunan Memuji 1

Selain pesan berupa teks, pesan yang dikirimkan oleh pengirim pesan juga berupa stiker yang berkaitan dengan pesan sebelumnya. Gambar 4 menunjukkan hal itu. Pada gambar itu, terdapat stiker dengan tulisan mantab jiwa yang mendukung kesantunan berbahasa.

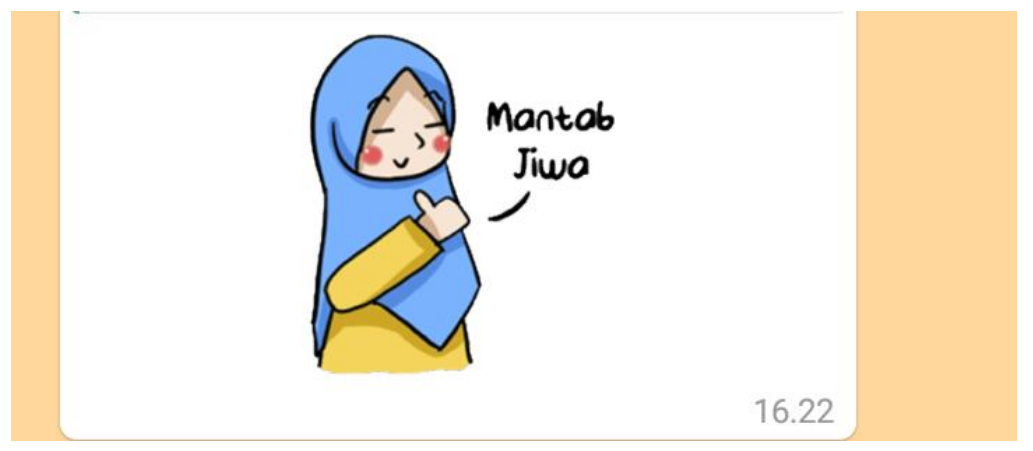

Gambar 4. Ungkapan yang Mengandung Kesantunan Memuji 2 


\section{Kesantunan Meminta}

Kesantunan meminta berkaitan dengan permintaan pengirim pesan atas informasi yang diharapkan. Bentuk kesantunan ini berkaitan dengan instruksi yang diberikan oleh pimpinan kepada anak buahnya. Pada gambar 5 berikut menunjukkan kesantunan meminta kepada seluruh penerima pesan. Sapaan bapak/ibu digunakan agar menciptakan rasa nyaman di antara penerima pesan. Ungkapan permohonan melalui kata mohon digunakan untuk memperhalus permintaan yang diharapkan untuk dikabulkan. Bahkan, emotikon berupa kedua tangan yang mengatup juga digunakan sebagai pelengkap bagi pesan ini semakin menambah kesantunan di dalamnya.

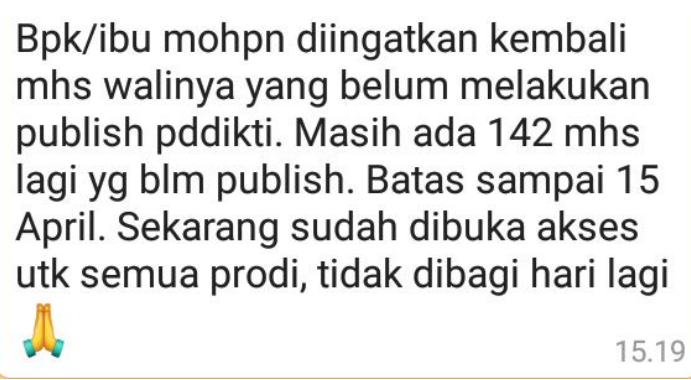

Gambar 5. Ungkapan yang Mengandung Kesantunan Meminta 1

Bentuk kesantunan yang lainnya dalam hal meminta juga terlihat pada gambar 6. Pada gambar itu, pengirim pesan berharap agar seluruh peserta pelatihan segera datang ke ruang pelatihan karena pembicara pelatihan sudah datang. Namun, permintaan itu disampaikan dengan bahasa yang santun dengan menggunakan kata monggo dan emotikon lengan semangat dan senyum manis sebagai pelengkap. Oleh karena itu, kesan permintaan untuk hadir tidak terkesan memaksa penerima pesan.

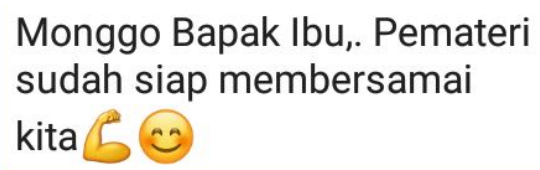

Gambar 6. Ungkapan yang Mengandung Kesantunan Meminta 2

\section{Fungsi Kesantunan}

Pada bagian ini, kesantunan memiliki beberapa fungsi yang mendukung kelancaran dalam berkomunikasi. Berikut ini adalah uraian detailnya.

\section{Fungsi Kompetitif}

Fungsi pertama adalah fungsi kompetitif. Fungsi ini digunakan oleh pengirim pesan agar penerima pesan mengikuti keinginan pengirim pesan. Gambar 7 menunjukkan pesan yang mengandung fungsi 
kesantunan kompetitif karena pengirim pesan memiliki harapan besar agar seluruh penerima pesan bisa menggunakan aplikasi pembelajaran yang sudah disiapkan kampus. Permintaan itu disampaikan melalui harapan. Hal itu terlihat dari kalimat yang digunakan, yaitu semua dosen dan mahasiswa menggunakan ILMU pasti cepat naik. Dalam kalimat itu, tidak ada ungkapan yang keras untuk menyuruh penerima pesan segera melakukannya tetapi berupa harapan. Oleh karena itu, penerima pesan bisa menjadi tersentuh, bukan tersinggung.

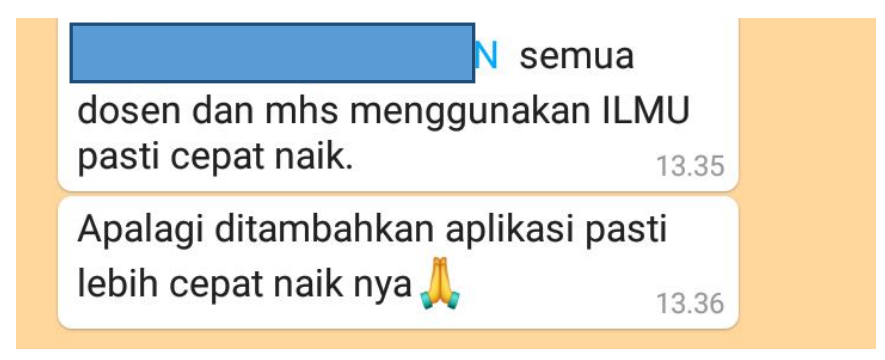

Gambar 7. Ungkapan yang Mengandung Fungsi Kompetitif

\section{Fungsi Menyenangkan}

Gambar 8 menunjukkan komunikasi yang mengandung fungsi kesantunan menyenangkan. Kata yang dipilih dalam pesan berupa ungkapan yang menimbulkan rasa menyenangkan dalam hati penerima pesan. Kata itu adalah menarik, mantabb, dan toppp. Ketiganya akan memancing rasa menyenangkan dari pengirim pesan sebelumnya.

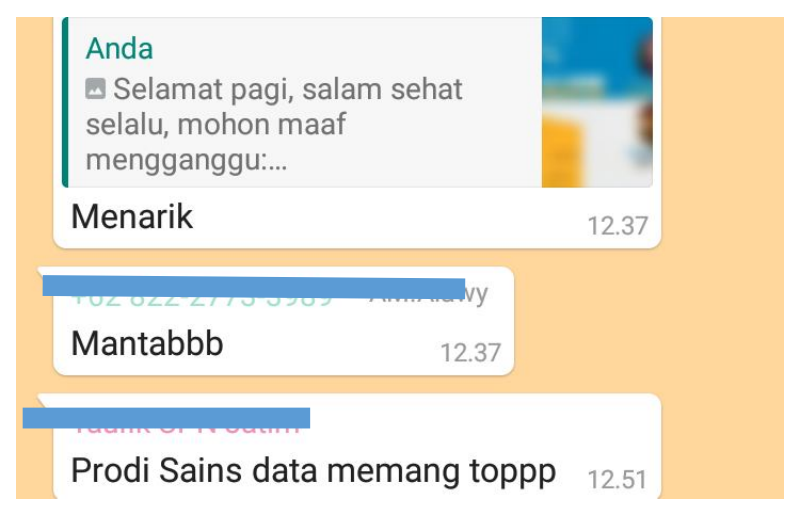

Gambar 8. Ungkapan yang Mengandung Fungsi Menyenangkan 1

Tak hanya komunikasi dengan mengirimkan kalimat pujian, ungkapan berupa rasa terima kasih juga menunjukkan fungsi kesantunan menyenangkan. Dengan terima kasih yang diberikan oleh pengirim pesan pada gambar 9 bisa memberikan rasa menyenangkan bagi pengirim pesan sebelumnya. Bahkan emotikon tangan mengatup dan senyum riang semakin menambahkan kesantunan yang ada. Harapan dengan kata semoga juga termasuk aspek kesantunan. 


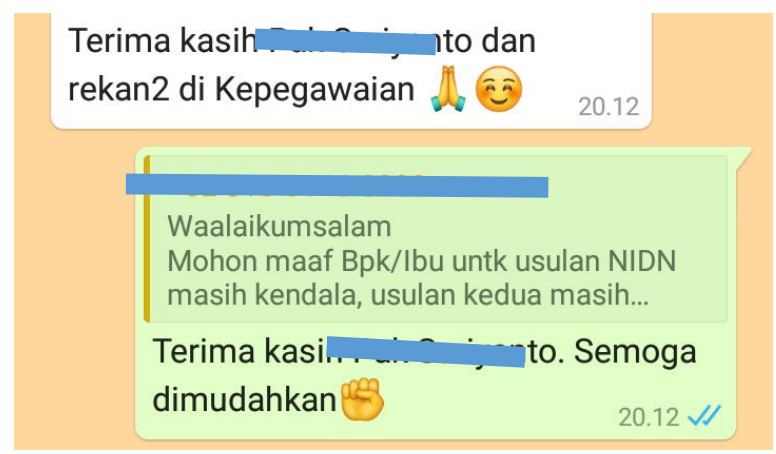

Gambar 9. Ungkapan yang Mengandung Fungsi Menyenangkan 2

\section{Fungsi Kerja Sama}

Fungsi kerja sama mencakup banyak aspek. Akan tetapi, aspek mengumumkan dan mengajarkan lebih banyak muncul dalam konteks pekerjaan. Pada gambar 10 menunjukkan aspek fungsi kesantunan mengumumkan. Informasi yang disampaikan dalam pengumuman itu menjadi aspek penting dalam komunikasi yang terjadi. Pilihan kata Yth Bapak Ibu menunjukkan kesantunan sehingga pengumuman yang diberikan tidak membuat penerima pesan tertekan.

\section{Yth Bpk Ibu Dosen ini ada Surat \\ Pemberitahuan ttg Pemutahiran Data \\ Profil Author Sinta. Monggo Bpk Ibu \\ Update data di SINTA is \\ 16.32}

Gambar 10. Ungkapan yang Mengandung Fungsi Kerja Sama 1

Selanjutnya, gambar 11 berisi pesan untuk mengajarkan kepada penerima pesan agar melakukan hal yang diharapkan oleh pengirim pesan. Dalam pesan itu, pengirim pesan menginginkan agar protokol kesehatan selama kegiatan tetap dijaga agar seluruh peserta pelatihan tetap sehat dan terhindar dari Covid-19. Harapan itu tidak terkesan menggurui karena ada kata saran dan sebaiknya yang digunakan sebagai pembuka pesan. Bahkan, sebaiknya diulang kembali di tengah-tengah pesan sehingga menambah kesantunan dalam komunikasi. Aspek kesantunan semakin berfungsi dengan baik dalam hal fungsi kerja sama dengan penambahan kata terima kasih di akhir pesan dan emotikon orang bermasker. 
saran,_.....y. sebaiknya semua jendela ruangan dibuka sbg gantinya ac, spy sirkulasi udaranya bagus. dan hindari makan minum dlm satu ruangan secara bersama2. sebaiknya makan minum di ruangan sendiri, atau sekalian dibawa pulang saja. shg masker dipastikan tdk pernah lepas selama acara. terima kasih, bu

Gambar 11. Ungkapan yang Mengandung Fungsi Kerja Sama 2

\section{Fungsi Bertentangan}

Terakhir, fungsi bertentangan juga terlihat dalam komunikasi di grup WA pada hal-hal yang berlawanan dengan prinsip masing-masing pengirim pesan saat mendapatkan pesan sebelumnya. Gambar 12 menunjukkan fungsi bertentangan. Isi pesan di dalamnya berupa sanggahan atas informasi yang disampaikan sebelumnya. Namun, pesan yang disampaikan bukan berupa ungkapan yang bisa menjatuhkan harga diri pengirim pesan sebelumnya di grup WA. Pengirim pesan pada gambar 12 menggunkan perumpamaan buah manga agar penerima pesan terselamatkan muka negatifnya. Bahkan kata maaf dan frasa sekedar ungkapan untuk terus mencari jalan terbaik mendukung tercapainya fungsi ini.

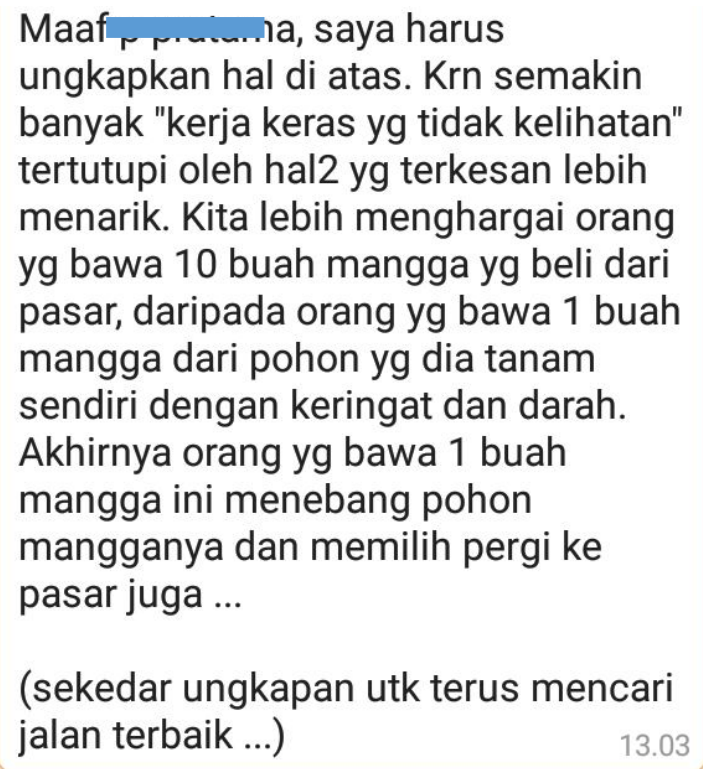

Gambar 12. Ungkapan yang Mengandung Fungsi Pertentangan 1

Bahkan, pada gambar 13, pesan yang dikirimkan dilengkapi dengan kalimat mohon maaf jika ada yang kurang berkenan. Barakallah. Kalimat itu tentu sangat menyelamatkan muka penerima pesan setelah membaca pesan-pesan sebelumnya. Emotikon tangan mengatup juga digunakan. Padahal isi pesan sangat 
menyinggung penerima pesan, tetapi keberadaan kalimat itu membuat fungsi kesantunan bekerja dengan baik.

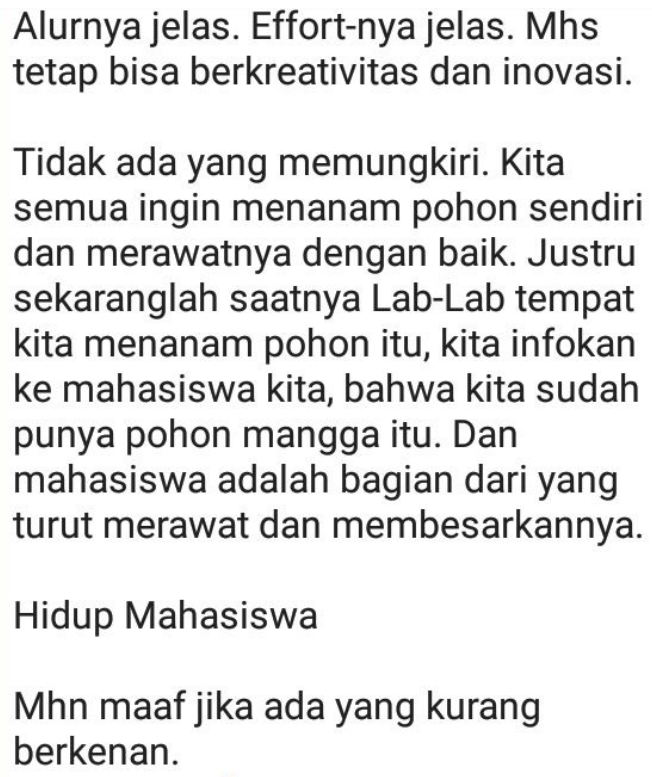

Gambar 13. Ungkapan yang Mengandung Fungsi Pertentangan 2

\section{SIMPULAN}

Berdasarkan penelitian yang sudah dilakukan, ditemukan 3 bentuk kesantunan dan 5 fungsi kesantunan. Bentuk kesantunan meliputi kesantunan meminta, bertanya, dan memuji. Seluruh bentuk kesantunan itu banyak digunakan saat berkomunikasi melalui grup WA selama pandemik Covid-19. Sementara itu, fungsi kesantunan meliputi fungsi kompetitif, menyenangkan, kerja sama, dan bertentangan. Seluruh fungsi itu bekerja dengan baik dalam komunikasi. Seluruh muka negatif yang ditimbulkan selama komunikasi bisa berkurang. 


\section{DAFTAR PUSTAKA}

Andriyani, A.A. Ayu Dian \& Jayantini, I Gusti Agung Sri Rwa. 2020. Perempuan dan Pesan di Media Sosial pada Masa Pandemi Covid-19: Analisis Strategi Kesantunan. Prosiding Webinar Nasional Peranan Perempuan/Ibu dalam Pemberdayaan Remaja di Masa Pandemi Covid-19 Universitas Mahasaraswati Denpasar.

Anugrah, Mayang Sari, Ike Revita, \& Rina Marnita. 2020. Kesantunan Linguistik dalam Interaksi Jual Beli di Pasar Raya Solok. Lingua, 17 (2), 218-232

Leech, Geoofrey. (1993). Prinsip-prinsip Pragmatik. Yogyakarta: Graha Ilmu.

Oktavianus dan Revita. (2013). Kesantunan dalam Bahasa Minangkabau. Padang: Universitas Andalas.

Rahayu, Sri. 2019. Analisis Kesantunan Berbahasa Media Sosial Instagram: Kajian Pragmatik. Skripsi. Universitas Muhammadiyah Sumatera Utara.

Jauhari, Edy. 2018. Alat-Alat Kesantunan Kritik dalam Masyarakat Jawa Surabaya: Kajian Pragmatik. Mozaik Humaniora, 18 (2): 167-177 